\title{
Levels of mannose-binding lectin (MBL) associates with sepsis-related in-hospital mortality in women
}

\author{
Sofie Jacobson ${ }^{1 *}$, Peter Larsson ${ }^{1}$, Anna-Maja Åberg ${ }^{1}$, Göran Johansson ${ }^{1}$, Ola Winsö ${ }^{1}$ and Stefan Söderberg ${ }^{2}$
}

\begin{abstract}
Background: Mannose-binding lectin (MBL) mediates the innate immune response either through direct opsonisation of microorganisms or through activation of the complement system. There are conflicting data whether MBL deficiency leads to increased susceptibility to infections or not. The aim of this study was to determine if low levels of mannose-binding lectin (MBL) predict sepsis development, sepsis severity and outcome from severe sepsis or septic shock.

Method: Patients aged 18 years or more with documented sepsis within $24 \mathrm{~h}$ after admission to the intensive care unit were included if they had participated in a health survey and donated blood samples prior to the sepsis event. A subset of these patients had stored plasma also from the acute phase. Two matched referents free of known sepsis were selected for each case. Plasma levels MBL were determined in stored samples from health surveys (baseline) and from ICU admission (acute phase). The association between MBL and sepsis, sepsis severity and inhospital mortality were determined with $1300 \mathrm{ng} / \mathrm{mL}$ as cut-off for low levels.
\end{abstract}

Results: We identified 148 patients (61.5\% women) with a first-time sepsis event 6.5 years (median with IQR 7.7) after participation in a health survey, of which 122 also had samples from the acute septic phase. Both high MBL levels in the acute phase (odds ratio [95\% confidence interval]) (2.84 [1.20-6.26]), and an increase in MBL levels from baseline to the acute phase (3.76 [1.21-11.72]) were associated with increased risk for in-hospital death in women, but not in men (0.47 [0.11-2.06]). Baseline MBL levels did not predict future sepsis, sepsis severity or in-hospital mortality.

Conclusions: An increase from baseline to the acute phase as well as high levels in the acute phase associated with an unfavourable outcome in women.

Keywords: Sepsis, Mannose-binding lectin, Sex, Case-referent study

\section{Background}

Severe sepsis is a life-threatening syndrome where little is known about factors determining susceptibility for developing the syndrome and severity of the syndrome once developed. Potentially, biomarkers could be used for identifying those at risk for severe sepsis needing

\footnotetext{
* Correspondence: sofie.jacobson@umu.se

'Department of Surgical and Perioperative Sciences, Anesthesiology and Intensive Care Medicine, Umeå University, SE-901 87 Umeå, Sweden Full list of author information is available at the end of the article
}

aggressive treatment, which is subject for intensive studies [1-4]. With advances in recombinant techniques, targeted substitution therapies are forthcoming and one of the challenges will be to define which patients will benefit from such therapies [5-7].

Mannose-binding lectin (MBL) is a serine protease belonging to the collectin family and is believed to be an important factor in the innate immune system, the first line host defence. With its pattern-recognizing ability, MBL binds to the surface of a wide range of microorganisms, 
although not all, thus functioning either as a direct opsonin, or through activation of the complement system, thereby enhancing phagocytosis of microorganisms by macrophages and neutrophils [8].

There are several known mutations in the structural $M B L 2$-gene and its promoter regions located at the long arm of chromosome 10, resulting in a large number of haplotypes. This genetic polymorphism is associated with different levels of MBL expression and activity [9-13].

There are several reports indicating that genotypes associated with low levels of MBL may predispose to certain forms of infection or impaired immune response, particularly in new-borns, but also in adults [14-17]. Other reports indicate that low levels of MBL may augment the humoral immune system [18-23]. However, there are considerable overlaps in MBL concentrations between different genotypes, and inter-individual variability among individuals with identical genotypes is significant $[10-13,24,25]$. Different definitions and cut-off values have been used to define MBL deficiency [17, 26-29] and genotypes associated with low MBL production are common, as high as $25-30 \%$ in certain populations $[25,29]$.

Several studies on the association of MBL genetic polymorphism and/or MBL plasma levels with severe infections, sepsis and septic shock, have shown an increased risk of sepsis development and unfavourable outcome in MBL deficient patients [27, 28, 30, 31]. However, there are conflicting results [26, 32-34].

In this nested case-referent study we hypothesized that low MBL levels associate with increased risk of future sepsis, and its severity, and in contrast, that high levels associates with decreased risk of sepsis and sepsis related mortality. Furthermore, that the MBL-associated risk is similar in men and women.

\section{Material and methods}

Design and methods have been previously reported [35]. Shortly, cases were identified retrospectively within health survey cohorts and biomarkers were analyzed in blood samples collected at the health surveys (baseline) and when available, in blood samples collected at admission to the intensive care unit (acute phase).

A total of 797 patients were admitted with a diagnosis of sepsis at the Intensive Care Unit, Umeå University Hospital, Sweden, between 1 March 1988 and 31 October 2008.

The diagnosis of sepsis and the severity of sepsis were confirmed retrospectively by reviewing hospital records, including results from biochemical, microbiological, and radiological examinations.

Of the 797 patients, 148 had prior to the septic event participated in one of four population-based health studies in Northern Sweden: the Västerbotten Intervention Program (VIP), the Northern Sweden MONItoring Of trends and Determinants in CArdivascular Disease (MONICA) survey, the Mammary Screening Program (MSP), and the Northern Sweden Maternity Cohort (NSMC). The contribution of cases from each survey was 80 (VIP), 4 (MONICA), 42 (MSP), and 22 (NSMC). The Northern Sweden Health and Disease Study (NSHD S) which includes the three former studies, and the Northern Sweden Maternity Cohort (NSMC) are described in detail in our previous report [35].

Patients aged 18 years or older were included if they had a diagnosis of sepsis within $24 \mathrm{~h}$ after admittance to the ICU. Only the first event was included for patients with multiple admissions due to sepsis. The Third International Consensus Definitions for Sepsis and Septic Shock (Sepsis-3) were used [36]. Acute Physiology, Age, Chronic Health Evaluation II score (APACHE II) was calculated for assessment of severity of illness at admission [37]. Sequential Organ Failure Assessment Score (SOFA) was calculated as a marker for organ dysfunction and disease severity [38].

Data on length of stay, mortality, referral patterns, and reasons for admission, co-morbidities, and sources of infection, primary infection sites and causative microorganisms were collected. Microbiological cultures acquired within $48 \mathrm{~h}$ before or after admission to the ICU were considered relevant. Pre-existing diseases were defined according to Knaus et al. [37].

For each case, two referents without any episode of sepsis and being alive at the date of the case admission to ICU were chosen and matched for age $( \pm 2$ years), gender, health survey, and time of blood sampling ( \pm 30 days). Matching on smoking $(y / n)$ was incomplete due to missing information, mainly in the MSP.

In addition, 122 out of 148 patients had also retrievable samples collected at ICU admission (the acute phase). Thus, 122 patients had samples from both the health survey examination (baseline) and from admission to the ICU (the acute phase).

The study protocol was approved by the Regional Ethical Review Board in Umea and by the Swedish National Computer Data Inspection Board, and complies with the Declaration of Helsinki. All participants gave written informed consent for future use of data and blood samples.

\section{Chemical analyses}

MBL in plasma was analysed in duplicates using a commercially available ELISA (MBL Oligomer ELISA Kit 029, BioPorto Diagnostics, Gentofte, Denmark) in accordance with the instructions from the manufacturer. The absorbance was read on a spectrophotometer (Labsystems Multiskan MS, Triad Scientific Inc., USA). The range of the assay was 0 to $4000 \mathrm{ng} / \mathrm{mL}$. The 
distribution of MBL in healthy Danish blood donors analysed with the same assay was provided by the manufacturer. There was no significant difference in MBL distribution when comparing the Danish cohort with our study cohort (Supplementary Table 5 and 6).

\section{Statistical analyses}

Data are presented as numerical values or percentages. Continuous data are presented as median with interquartile range. For comparisons, Fisher's exact, Mann-Whitney U-tests or Wilcoxons Signed Rank test were used when appropriate. Spearman correlation test was used for correlation. Since cases and referents had the same follow-up time within strata in this nested and matched case-referent study, logistic regression analysis (rather than Cox regression) using the conditional maximum likelihood routine designed for matched analysis was used to estimate odds ratios with $95 \%$ confidence intervals (CI), and the influence of MBL on future sepsis was tested in a univariable model. Non-conditional logistic regression (only cases) analysis was used to calculate the risk for in-hospital death. Mannose-binding lectin was tested as a categorical variable with $1300 \mathrm{ng} / \mathrm{ml}$ as cut-off for low levels [27]. The accuracy of this cut-off was tested with Receiver Operator Characteristic (ROC) graphs with calculation of the area under the curve (AUC).

The change in MBL levels from baseline to the acute phase (the difference in MBL levels between base line and the acute phase) was also tested as a categorical variable. The cut-off was set at zero, with positive values representing an increase and negative values representing a decrease from baseline to the acute phase. The accuracy of this cut-off was also tested with ROC analysis. A $p$-value $<0.05$ was considered significant, and all $p$-values reported are twosided. SPSS ver. 24 was used for statistical analysis.

\section{Results}

Sixty-one percent of both cases and referents were women (matched), and there was no difference in age between cases and referents (matched) but women were younger than men at baseline survey, 49.8 years and 53.2 years, respectively $(P=0.003)$. Cases had marginally higher BMI than referents $(P=0.04)$ but the prevalence of diabetes, hypertension, hypercholesterolemia and smoking did not differ (Table 1).

Circulating MBL levels at baseline did not differ between cases and referents $(P=0.5)$ (Table 2). However, when comparing men and women in the whole cohort women had slightly lower levels at baseline than men $(P=0.04)$, but there was no difference between female cases and their referents $(P=0.5)$, or between male cases and their referents $(P=0.9)$ (Fig. 1). Further, the distribution of low and high MBL levels (cut-off $1300 \mathrm{ng} / \mathrm{mL}$ ) did not differ between cases and referents or between men and women (Table 2).

Patient characteristics at ICU admission are shown in Table 3. Women were younger when developing sepsis $(P=0.04)$, and the period between the baseline survey and the sepsis event was 7.4 years (IQR 7.8) for men and 5.9 years (IQR 8.1$)$ for women $(P=0.04)$. Of the events, $67 \%$ were classified as severe sepsis and $33 \%$ as the most severe form, the septic shock. Severity of sepsis, APAC HE II- and SOFA score, length of stay, ICU- and inhospital mortality did not differ between men and women. There were no differences in co-morbidities, sources of infection and infecting microorganisms between men and women except for infections with gram negative rods which was slightly more frequent in men $(P=0.04)$.

MBL levels at ICU admission (samples available from 122 patients) did not differ between men and women $(P=0.7)$. However, MBL levels in the acute phase were significantly lower than baseline levels in both men and

Table 1 Subject characteristics at baseline surveys

\begin{tabular}{|c|c|c|c|c|c|c|}
\hline & $n=$ cases/referents & Cases & $95 \% \mathrm{Cl}$ & Referents & $95 \% \mathrm{Cl}$ & $p$ \\
\hline Age years & $148 / 296$ & 51.1 & $49.0-53.2$ & 51.1 & $49.6-52.6$ & (matched) \\
\hline Female gender, \% & $91 / 182$ & 61.5 & $53.6-69.4$ & 61.5 & $55.9-67.1$ & (matched) \\
\hline $\mathrm{BMI}, \mathrm{kg} / \mathrm{m}^{2}$ & $116 / 229$ & 27.6 & $26.5-28.7$ & 26.4 & $25.8-26.9$ & 0.04 \\
\hline Reduced glucose tolerance, \% & $80 / 151$ & 35.0 & $24.3-45.7$ & 23.8 & $17.0-30.7$ & 0.16 \\
\hline Daily smoker, \% \# & $116 / 237$ & 28.4 & $20.1-36.8$ & 28.7 & $22.9-34.5$ & (matched) \\
\hline Hypertension, \% & $83 / 158$ & 55.4 & $44.5-66.4$ & 43.0 & $35.2-50.8$ & 0.08 \\
\hline Systolic BP, mmHg & $83 / 158$ & 135 & $130-139$ & 132 & $129-135$ & 0.34 \\
\hline Diastolic BP, mmHg & $83 / 158$ & 82 & $80-85$ & 82 & 80-83 & 0.74 \\
\hline Cholesterol, mmol/La & $83 / 155$ & 5.7 & $5.4-5.9$ & 6.0 & $5.8-6.2$ & 0.06 \\
\hline
\end{tabular}

Values reported are means or percentages $\%$ with $95 \% \mathrm{Cl}$. Hypertension was defined as systolic $\mathrm{BP}>140 \mathrm{mmHg}$ and/or diastolic $\mathrm{BP}>90 \mathrm{mmHg}$ and/or antihypertensive treatment. Reduced glucose tolerance included any of IFG, IGT or DM. Referents were matched with cases based on age, sex and (if available) smoking status

Abbreviations: DM Diabetes mellitus, IFG Impaired fasting glucose, IGT Impaired glucose tolerance, BP Blood pressure 
Table $2 \mathrm{MBL}$ concentration $(\mathrm{ng} / \mathrm{mL})$ at baseline survey for cases and referents

\begin{tabular}{lllll}
\hline & Cases & Referents & Cases & Referents \\
\hline & $n$ & $n$ & MBL $(\mathrm{ng} / \mathrm{mL})$ & $\mathrm{MBL}(\mathrm{ng} / \mathrm{mL})$ \\
$\mathrm{MBL}$ conc. $(\mathrm{ng} / \mathrm{mL})$ & 148 & 296 & $1646($ IQR 3095) & $1401($ IQR 2305) \\
$\mathrm{MBL}<1300(\mathrm{ng} / \mathrm{mL})$ & $63(42.6 \%)$ & $140(47.3 \%)$ & $284($ IQR 541) & $434($ IQR 576) \\
$\mathrm{MBL}>=1300(\mathrm{ng} / \mathrm{mL})$ & $85(57.4 \%)$ & $156(52.7 \%)$ & $2863($ IQR 2170) & 2671 (IQR 2101) \\
\hline
\end{tabular}

Data are presented as numbers (\%) and median with interquartile range (IQR)

women ( $P=0.03$ and $P<0.05$, respectively) (Fig. 2$)$. Comorbidities, sources of infection and infecting microorganisms did not differ in those with low MBL levels defined as levels below $1300 \mathrm{ng} / \mathrm{mL}$ compared to patients with MBLlevels above $1300 \mathrm{ng} / \mathrm{mL}$ (data not shown).

Circulating MBL levels at baseline did not correlate with age $(r=-0.02, P<0.8)$, BMI $(r=-0.02, P<0.9)$, fasting or post-load glucose levels, $(r=0.05, P=0.6$ and $r=-0.07, P=0.5$, respectively), or with systolic or diastolic blood pressures $(r=-0.07, P=0.6$ and $r=-0.15$, $P=0.2$, respectively). Similarly, MBL levels in the acute phase did not correlate with age $(r=0.09, P=0.3)$, BMI $(r=-0.02, P=0.9)$, APACHE II score $(r=0.10, P=0.3)$, or SOFA score $(r=0.08, P=0.4)$. Circulating levels of MBL in the acute phase did not correlate to MBL at baseline $(r=0.004, P=1.0)$. Correlation analysis stratified by sex did not add any more information, neither at baseline nor in the acute phase (data not shown).

Low levels at baseline expressed as circulating MBL below $1300 \mathrm{ng} / \mathrm{mL}$ did not predict a future sepsis event (0.82 [0.55-1.23]), or increased severity; severe sepsis (0.94 [0.58-1.54]), septic shock (0.64 [0.32-1.27]), or hospital death (1.29 [0.54-3.08]). Similar point estimates were seen when stratified for sex. Several other cut-offs were also tested, but lower levels (than $1300 \mathrm{ng} / \mathrm{mL}$ ) did not associate with future sepsis development, sepsis severity or hospital outcome (Supplementary Table 4).

Women who died had significantly higher levels in the acute phase than surviving women $(P=0.005)$, and they had also higher levels than men who died $(P=0.02)$ (Fig. 3).

Intra-individual MBL levels decreased significantly from baseline to the acute phase in women who survived $(P=0.002)$. Further, there was a significant difference in the change of MBL levels in surviving women compared to non-surviving women $(P=0.003)$. In men, the intra individual changes did not differ between survivors or non-survivors $(P=0.6)$ (Fig. 4).

The association between MBL levels in the acute phase and in-hospital death was analysed, with $1300 \mathrm{ng} / \mathrm{mL}$ as cut-off. The accuracy of the chosen cut-off $(1300 \mathrm{ng} / \mathrm{mL})$ was tested in a ROC analysis showing a diagnostic accuracy of $65.6 \%$ at $1319 \mathrm{ng} / \mathrm{mL}$, with a sensitivity of $68.1 \%$ and specificity of $57.1 \%$ for the whole group. AUC was $0.60(0.48-0.72,95 \% \mathrm{CI}), p=0.044$. For women, the ROC analysis showed a diagnostic accuracy of $73.3 \%$ at $1319 \mathrm{ng} / \mathrm{mL}$, with a sensitivity of $72.4 \%$ and specificity of $76.5 \%$. AUC was $0.73(0.59-0.86,95 \% \mathrm{CI}), P=$ 0.0008 . For men, no discrimination point was detected (Supplementary Figures 7, 8 and 9, respectively).

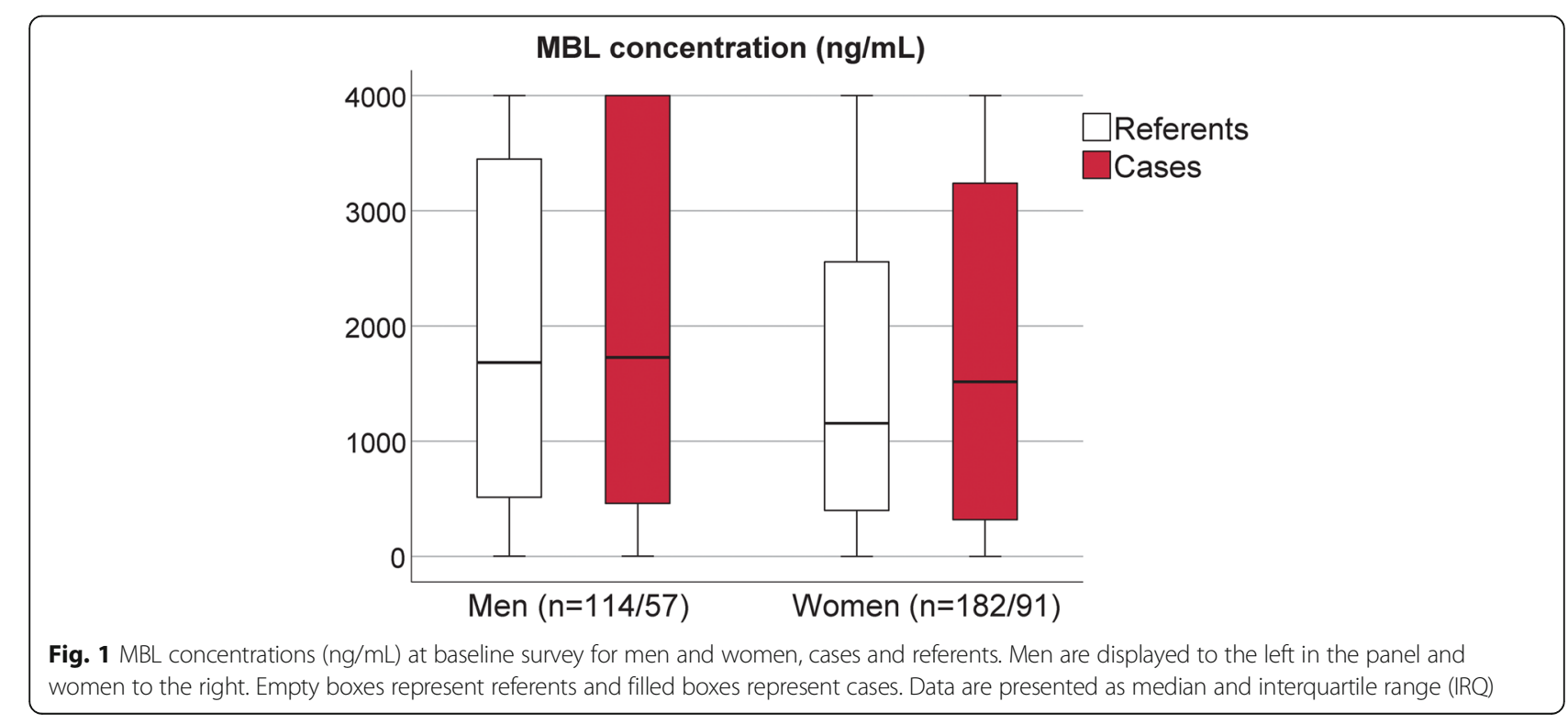


Table 3 Patient characteristics at ICU admission

\begin{tabular}{|c|c|c|c|}
\hline & All patients $(n=148)$ & Men $(n=57)$ & Women $(n=91)$ \\
\hline Age years & 60.7 (IQR 18.3) & 63.4 (IQR 16.5) & $57.2(\mathrm{IQR} 18.0)$ \\
\hline Years between survey and sepsis & $6.5(\mathrm{IQR} 7.7)$ & 7.4 (IQR 7.8) & $5.9($ IQR 8.1$) *$ \\
\hline $\mathrm{BMI}(n=116,52 / 64)$ & 26.7 (IQR 6.0) & $26.0(\mathrm{IQR} 6.2)$ & 26.9 (IQR 7.0) \\
\hline \multicolumn{4}{|l|}{ Disease scores } \\
\hline APACHE II Score & 18.0 (IQR 9) & $17.0(\mathrm{IQR} 10)$ & 18.0 (IQR 9) \\
\hline SOFA score & $7.0($ (IQR 5) & 7.0 (IQR 5) & $7.0($ (IQR 6) \\
\hline \multicolumn{4}{|l|}{ Disease severity, $\mathrm{n}(\%)$} \\
\hline Severe sepsis & 99 (66.9\%) & $42(74 \%)$ & $57(63 \%)$ \\
\hline Septic shock & 49 (33.1\%) & $15(26 \%)$ & $34(37 \%)$ \\
\hline ICU mortality & $27(18.2 \%)$ & $10(17.5 \%)$ & $17(18.7 \%)$ \\
\hline Hospital mortality & $32(21.6 \%)$ & $13(22.8 \%)$ & 19 (20.9\%) \\
\hline Hospital Length of stay & 17.5 (IQR 24.7) & 15 (IQR 25.5) & 18 (IQR 27) \\
\hline \multicolumn{4}{|l|}{ Co-morbidities, n (\%) } \\
\hline COPD & $4(2.7 \%)$ & $1(1.8 \%)$ & $3(3.3 \%)$ \\
\hline Congestive heart failure & $5(3.4 \%)$ & $3(5.3 \%)$ & $2(2.2 \%)$ \\
\hline Chronic renal insufficiency & $4(2.7 \%)$ & $2(3.5 \%)$ & $2(2.2 \%)$ \\
\hline Chronic liver disease & $0(0 \%)$ & $0(0 \%)$ & $0(0 \%)$ \\
\hline \multicolumn{4}{|l|}{ Diabetes, n (\%) } \\
\hline Insulin treatment & $11(7.4 \%)$ & $4(7.0 \%)$ & $7(7.7 \%)$ \\
\hline Other treatments & $8(5.4 \%)$ & $4(7.0 \%)$ & $4(4.4 \%)$ \\
\hline \multicolumn{4}{|l|}{ Cancer, n (\%) } \\
\hline Hematological & $9(6.1 \%)$ & $4(7.0 \%)$ & $5(5.5 \%)$ \\
\hline Localized & $20(13.5 \%)$ & $9(15.8 \%)$ & $11(12.1 \%)$ \\
\hline Metastatic & $11(7.4 \%)$ & $5(8.8 \%)$ & $6(6.6 \%)$ \\
\hline \multicolumn{4}{|l|}{ Immunosuppressants, n (\%) } \\
\hline Chronic steroids & $8(5.4 \%)$ & $3(5.3 \%)$ & $5(5.5 \%)$ \\
\hline Chemotherapy & $13(8.8 \%)$ & $7(12.3 \%)$ & $6(6.6 \%)$ \\
\hline Other immunosuppression & $12(8.1 \%)$ & $4(7.0 \%)$ & $8(8.8 \%)$ \\
\hline \multicolumn{4}{|l|}{ Primary infection site, n (\%) } \\
\hline Pneumonia & $24(16.2 \%)$ & $11(19 \%)$ & $13(14 \%)$ \\
\hline Abdominopelvic & $50(33.8 \%)$ & 19 (33\%) & 31 (34\%) \\
\hline Urinary tract & $20(13.5 \%)$ & $10(18 \%)$ & $10(11 \%)$ \\
\hline Other & $52(35.1 \%)$ & $17(30 \%)$ & $35(38 \%)$ \\
\hline Unknown & $5(3.4 \%)$ & $2(3.5 \%)$ & $3(3.3 \%)$ \\
\hline \multicolumn{4}{|l|}{ Infecting microorganism, n (\%) } \\
\hline Gram positive (cocci) & $62(14.0 \%)$ & $23(40.4 \%)$ & $39(42.9 \%)$ \\
\hline Gram negative (rods) & $40(27 \%)$ & $21(36.8 \%)$ & $19(20.9 \%) *$ \\
\hline Fungi & $11(7.4 \%)$ & $3(5.3 \%)$ & $8(8.8 \%)$ \\
\hline Virus & 9 (6.1\%) & $3(5.3 \%)$ & $6(6.6 \%)$ \\
\hline Negative cultures & $33(22.3 \%)$ & $13(22.8 \%)$ & $20(22.0 \%)$ \\
\hline
\end{tabular}

Data are presented as numbers (\%) or median and interquartile range (IQR)

* $p<0.05$ Mann-Whitney and Chi2. Abbreviations: APACHE Acute Physiology, Age and Chronic Health Evaluation, SOFA Sequential Organ Failure Assessment, CI Confidence interval, IQR Interquartile range, COPD Chronic obstructive pulmonary disease, ICU Intensive care unit 


\section{MBL concentration $(\mathrm{ng} / \mathrm{mL})$}

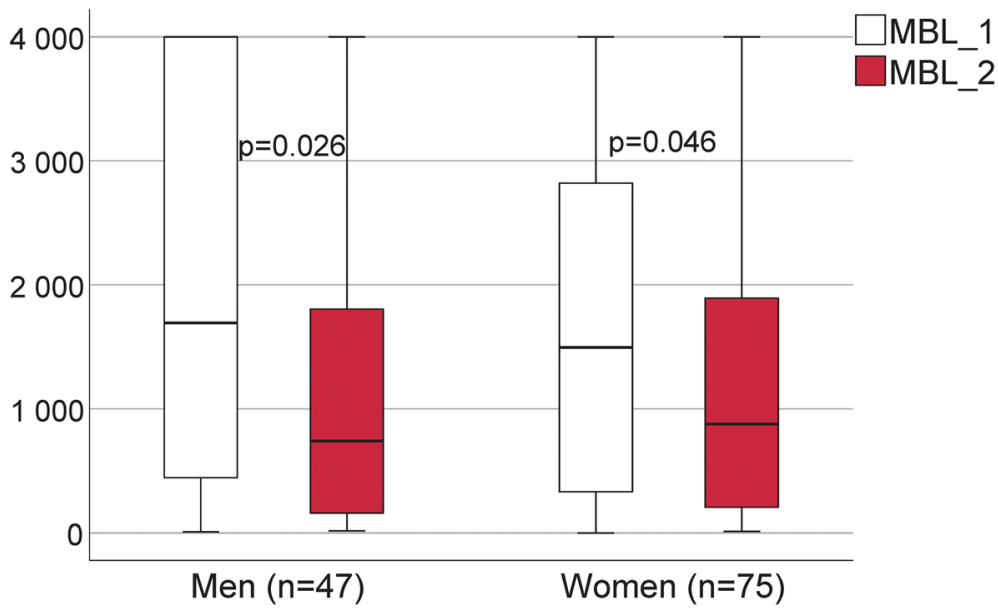

Fig. $2 \mathrm{MBL}$ concentrations $(\mathrm{ng} / \mathrm{mL})$ at baseline (MBL1) and in the acute phase (MBL2) for men and women. Men are displayed to the left in the panel and women to the right. Empty boxes represent baseline levels and filled boxes represent levels in the acute phase. Data are presented as median and interquartile range (IRQ). * $p<0.05$ MBL2 vs. MBL1 using Wilcoxon Signed Rank test

High levels associated with in-hospital death (2.84 [1.20-6.76]). In the stratified analysis, the association remained in women $(8.53$ [2.42-30.07] but not in men (0.59 [0.13-2.61]). The association remained for women even after adjustment for APACHE II score and for SOFA score separately (Fig. 5). Furthermore, an increase from baseline to the acute phase associated with hospital death in women $(3.76[1.27-11.72])$ but not in men (0.47 [0.11-2.06]) (Fig. 6). In a ROC analysis a diagnostic accuracy of $73.3 \%$ for the risk of in hospital death for women was found at an increase of $516 \mathrm{ng} / \mathrm{mL}$ from baseline to the acute phase, with a sensitivity of $75.9 \%$ and specificity of $64.7 \%$. AUC was 0.74 (0.61-0.87, $95 \% \mathrm{CI}), p=0.0001$ but no discriminating point could be seen in men, (Supplementary Figure 10 and 11, respectively).

\section{Discussion}

We report that low levels of MBL in a pre-sepsis state did not associate with a future sepsis event. Further, in

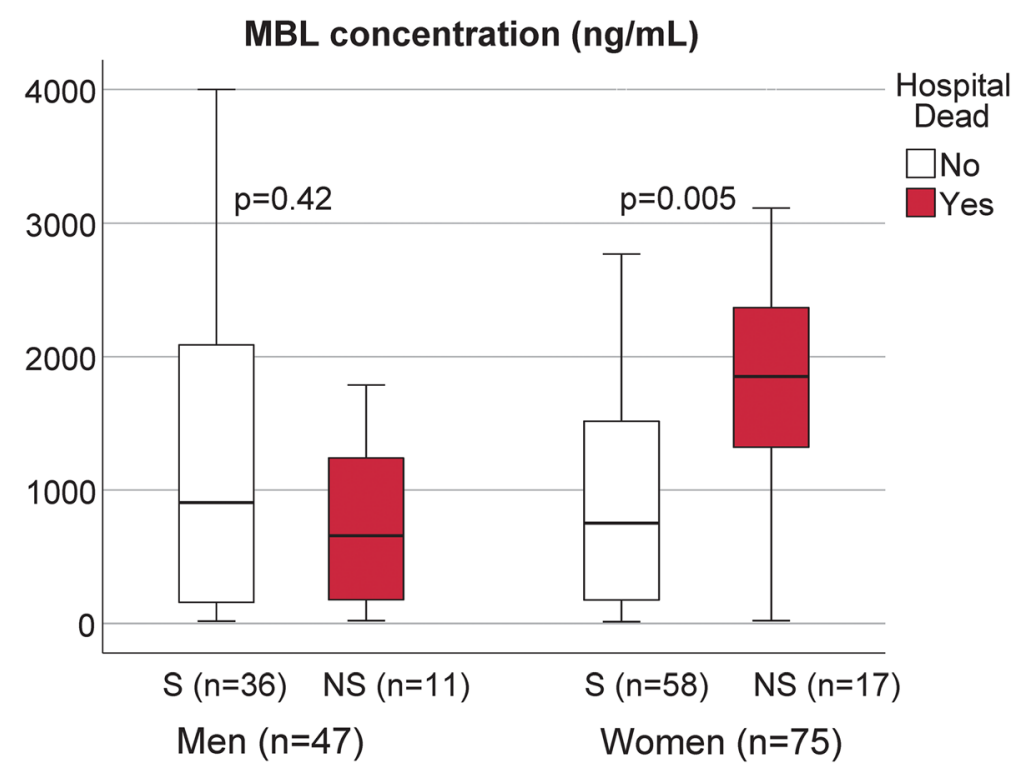

Fig. $3 \mathrm{MBL}$ concentrations ( $\mathrm{ng} / \mathrm{mL}$ ) in the acute phase for men and women, survivors (S) and non-survivors (NS). Men are displayed to the left in the panel and women to the right. Empty boxes represent survivors and filled boxes represent non-survivors. Data are presented as median and interquartile range (IRQ). * $p<0.05 \mathrm{NS}$ vs. S using Mann-Whitney U-test 
MBL concentration difference $(\mathrm{ng} / \mathrm{mL})$

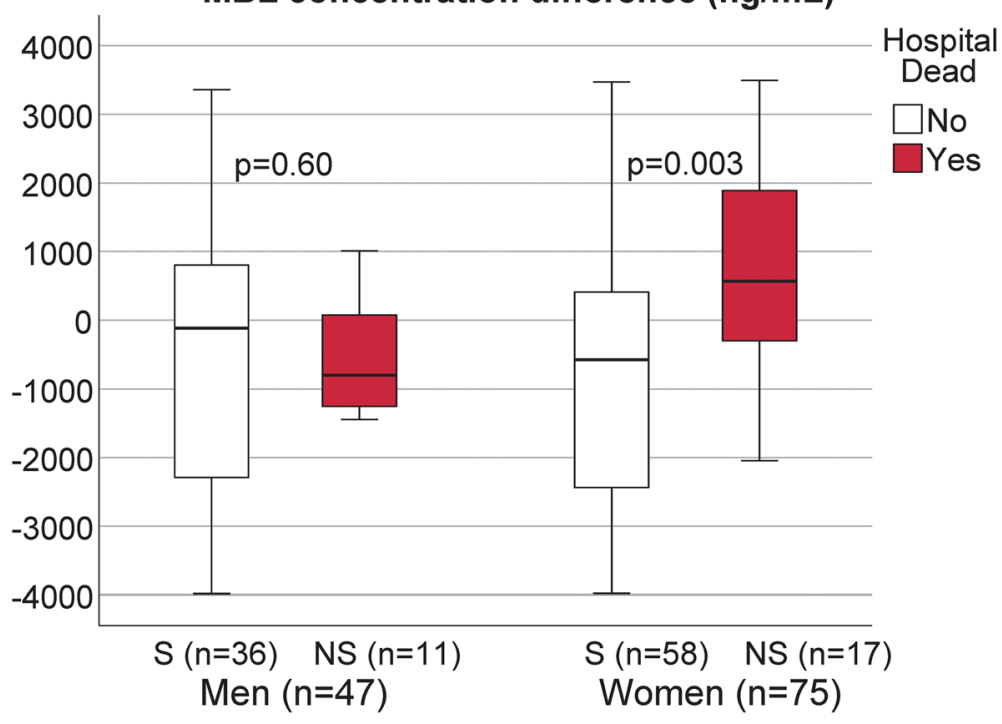

Fig. $4 \mathrm{MBL}(\mathrm{ng} / \mathrm{mL}$ ). Differences between MBL levels in the acute phase and at baseline for survivors (S) and non-survivors (NS) displayed for men and women separately. Men are displayed to the left in the panel, and women to the right. Empty boxes represent survivors and filled boxes represent non-survivors. For each box a negative value represent a decrease and a positive value represents an increase, (MBL_acute phase MBL_baseline) $>0=$ increase from baseline to the acute phase, (MBL_acute phase - MBL_baseline) $<0=$ decrease from baseline to the acute phase. Data are presented as median and interquartile range (IRQ). ${ }^{*} p<0.05$ NS vs. S using Mann-Whitney U-test

the acute phase of sepsis there were sex-related differences in MBL levels in relation to in-hospital mortality. Women who died in hospital had higher levels than surviving women. This association between MBL levels and outcome was not seen in men. Furthermore, an increase in MBL levels from baseline to the acute phase associated with hospital death in women but not in men. To our knowledge, the association between circulating MBL levels and sepsis outcome in women has not been previously reported. This finding indicates the presence of sex-related differences related to innate immunity. It has been reported that 'resting' MBL levels in women may be higher than those of men of similar age, though others have not made such observation $[39,40]$.

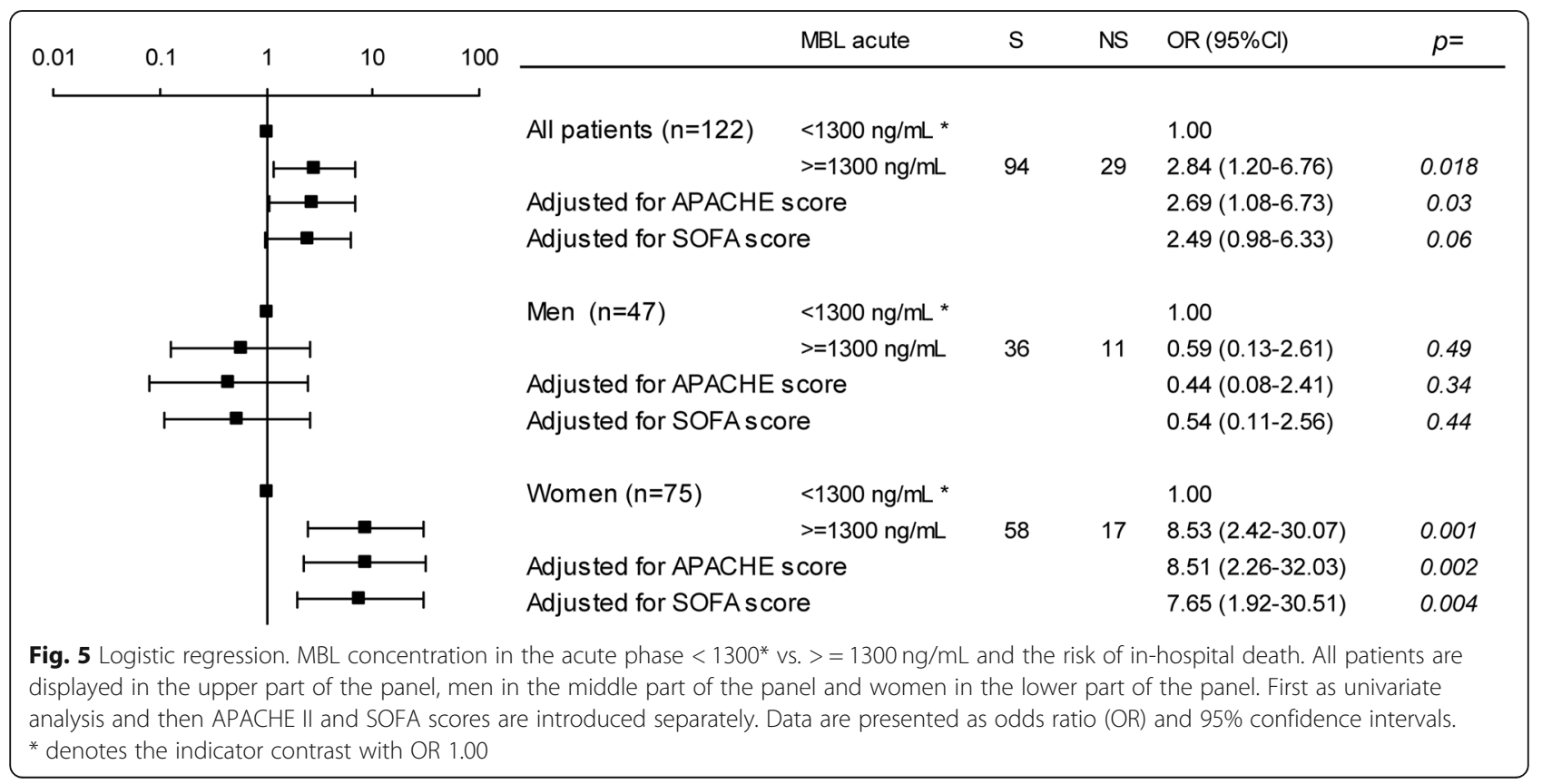




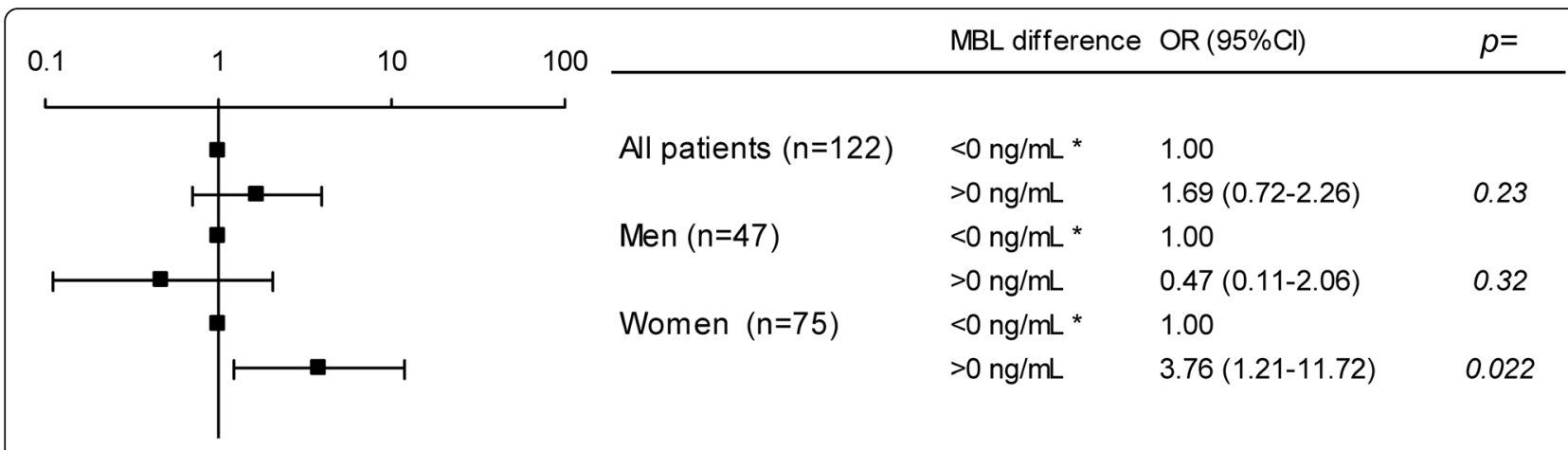

Fig. 6 Univariate logistic regression. The difference in MBL levels between the acute phase and baseline (MBL_acute phase - MBL_baseline) and the risk of in-hospital death. All patients are displayed in the upper part of the panel, men in the middle part of the panel and women in the lower part of the panel. Data are presented as odds ratio (OR) and 95\% confidence intervals. ${ }^{*}$ denotes the indicator contrast with OR 1.00

A second notable finding relates to changes in MBL levels in response to acute sepsis. Contrary to the expected, MBL levels decreased from baseline to the acute phase, especially in survivors, with a differential pattern in men and women.

The notion of MBL as an acute phase reactant stem from earlier findings. The promoter sequence of the MLB2 gene contains several consensus elements. As in other acute phase reactants, the transcription is enhanced by IL-6, dexamethasone and heat shock protein but inhibited by IL-1 $[41,42]$. However, MBLs function as an acute phase reactant has been questioned since there is considerable heterogeneity in the acute response in different settings and the influence of genetic polymorphism is substantial. A slower and less obvious MBL response to infection or surgical trauma compared with other acute phase reactants, as C-reactive protein, and variable responses in sepsis have been reported [43-46]. In an Australian study, $41 \%$ of patients with pneumonia and blood stream infection had stable MBL levels through their hospital stay [44]. Further, they found that patients who were MBL deficient at study entry, failed to demonstrate a positive acute phase response into the normal range. This diverge from our results were $35 \%$ of patients with baseline values less than $500 \mathrm{ng} / \mathrm{mL}$ increased to $1500 \mathrm{ng} / \mathrm{mL}$ or more in the acute phase. Differences in patient selection and timing of blood sampling may account for these discrepancies.

Another main finding was that low pre-sepsis MBL levels were not identified as a risk for severe sepsis, septic shock or unfavourable outcome. This is contrary to some interpretations that low MBL levels or a state of MBL deficiency is associated with increased risk for infection and development of SIRS, sepsis, septic shock, and even sepsis related death [28, 30, 47]. Also, in this respect there are conflicting data. In a large population based study were 9245 individuals were genotyped and followed 8 to 24 years, no evidence for significant differences in infectious disease or mortality in MBL deficient individuals versus controls was found [32]. A study on intensive care patients could not find any difference in frequency of MBL2-polymorfism between patients and controls at baseline, and between patients classified as having sepsis or not [34].

Considering the biological function of $\mathrm{MBL}$ as a pathogen recognizing molecule that either directly or mediated via the associated serinproteases MAPS2 activate the complement pathway and enhance phagocytosis, it would not be surprising if a ready access of functional MBL are beneficial in case of an infection. However, if this leads to an exaggerated complement activation it could result in extensive tissue damage, detrimental for the host. Of note in our cohort of patients, none of the women with the highest MBL values at baseline died in hospital, while an increase or high levels in the acute phase did not prove to be beneficial, at least not for women. In theory, this could imply that an abundance of MBL allowing a rapid pathogen recognition and early neutralization prevents further, uncontrolled activation of other cascade systems with subsequent excessive inflammatory response and organ dysfunction. A delayed response with an increase of MBL when other components of the innate immune system already are set into action may impose additional, non-beneficial inflammatory responses. Partly supporting this notion are data indicating beneficial effects of low MBL levels in different settings [18-21, 23, 48-50]. Thus, MBL may have different effects in different situations and in different phases of acute illness. An alternative explanation for the finding that patients who died had higher MBL levels than survivors could relate to dysfunctional MBL with reduced ligand binding and opsonin function which could lead to reduced phagocytosis and reduced clearance from the circulation and higher free MBL levels. However, the assay used in this study is considered to predominantly detect oligomeric or "functional" MBL. 
Most studies have not considered the possibility of sex-related differences and data are not presented stratified for sex. The value of MBL as a prognostic marker for out-come or patient selection for substitution or inhibitory therapy requires a deeper understanding of its action before implementation into clinical practice.

We were not able to find any association between MBL levels and degree of severity of acute sepsis, source of infection, infecting microorganism or other comorbidities. This was unexpected, since acute illness and co-morbidities might be expected to be accompanied by some degree of inflammation, also with corresponding MBL expression. A finding also unexpected in the light of reports that MBL deficiency is associated with recurrent respiratory infections and infections with gram-positive bacteria [16, 51-53]. However, the power to detect more subtle associations may have been restricted by the size of the study cohort.

Our results contradict findings from others that the presence of MBL variant alleles, and low MBL levels, associates with the development of sepsis, severe sepsis, and septic shock [28, 30]. There are also others who have not been able to show such distinct associations between severity of illness and MBL levels or genotype [26, 34, 44].

\section{Limitations in the study design}

In this study, only circulating plasma levels of MBL were determined, which ideally should have been combined with genotypes and studies of MBL function. More than 80 polymorphic sites are known, not all of known clinical relevance and only seven haplotypes are commonly found and studied were three different structural variants, B, C and D and the promoter haplotypes HY, LY and LX have a dominant effect on circulating MBL levels $[10,25,33]$. However, an individual's MBL levels cannot be determined from its genetic variant alone, since there are considerable inter-individual variations and other yet unknown factors probably influence circulating levels $[12,13,25,33]$. Still, a future study of sex-related MBL responses would ideally include genotyping. Further, due to lack of resources we were not able to specifically analyse MBL function, as with analysis of C4b deposit or MBL associated serine protease 2 (MASP-2).

The sample size was determined by access to preillness biomaterial, which affected the patient selection and limited the number of observations. For this reason, there is a majority of women of slightly younger age than the men. Patients do not entirely represent all patients consecutively admitted to the ICU, though their characteristics are representative for patients with sepsis at our ICU and we believe that there were sufficient observations to draw major conclusion from this explorative study.
The findings are empirical which can generate new hypothesis, and the study was not designed to assess possible pathophysiological mechanisms. Furthermore, the reported sex-related differences are similar to those previously reported for the adipokine leptin [35].

\section{Summary and conclusions}

In summary, we observed sex-related differences in MBL levels and kinetics related to sepsis survival. High levels or an increase of MBL in the acute phase of sepsis were associated with unfavourable outcome in women. We conclude that further evaluation of MBL response in acute sepsis should include a differentiated analysis with regard to gender. Further aspects of MBL response in sepsis needs to be elucidated before substitution with recombinant MBL or inhibitory therapy is considered in the future.

\section{Supplementary information}

Supplementary information accompanies this paper at https://doi.org/10. 1186/s12950-020-00257-1.

Additional file 1: Figure S7. Receiver operating characteristics, ROC analysis. ROC curve (left panel) for MBL concentrations in the acute phase (MBL2) in relation to in-hospital death for all patients $(n=122)$. In right panel sensitivity and specificity are shown for different MBL concentrations. An "optimal" cut-off point is shown in point A with a MBL concentration of $1319 \mathrm{ng} / \mathrm{mL}$ with a diagnostic accuracy of $65.6 \%$ and a sensitivity of $68.1 \%$ and a specificity of $57.1 \%$. Area under curve is 0.60 $(0.48-0.72,95 \% \mathrm{Cl}), p=0.044$.

Additional file 2: Figure S8. Receiver operating characteristics, ROC analysis. ROC curve (left panel) for MBL concentration in the acute phase (MBL2) for women $(n=75)$ in relation to in-hospital death. In right panel sensitivity and specificity are shown for different $M B L$ concentrations. An "optimal" cut-off point is shown in point A with a MBL concentration of $1319 \mathrm{ng} / \mathrm{mL}$ with a diagnostic accuracy of $73.3 \%$ and a sensitivity of $72.4 \%$ and a specificity of $76.5 \%$. Area under curve is $0.73(0.59-0.86$, $95 \%(\mathrm{Cl}), p=0.0008$.

Additional file 3: Figure S9. ROC curve (left panel) for MBL concentration in the acute phase (MBL2) for men $(n=47)$ in relation to in-hospital death. In right panel sensitivity and specificity are shown for different $M B L$ concentrations. Area under curve is $0.42(0.24-0.60,95 \% \mathrm{Cl})$, $p=0.81$.

Additional file 4: Figure S10. ROC curve (left panel) for the difference in $\mathrm{MBL}$ concentration between the acute phase $(\mathrm{MBL} 2)$ and baseline (MBL1) for women $(n=75)$ in relation to in-hospital death. In right panel sensitivity and specificity are shown. An "optimal" cut-off point is shown in point $A$ with a MBL concentration difference of $516 \mathrm{ng} / \mathrm{mL}$ with a diag nostic accuracy of $73.3 \%$ and a sensitivity of $75.9 \%$ and a specificity of $64.7 \%$. Area under curve is $0.74(0.61-0.87,95 \% \mathrm{Cl}), p=0.0001$.

Additional file 5: Figure S11. ROC curve (left panel) for the difference in $\mathrm{MBL}$ concentration between the acute phase (MBL2) and baseline (MBL1) for men $(n=47)$ in relation to in-hospital death. In right panel sensitivity and specificity are shown. Area under curve is $0.45(0.26-0.63$, 95\%(l), $p=0.71$.

Additional file 6: Table S4. MBL at baseline and risk for future sepsis development.

Additional file 7: Table S5. Comparison of MBL distribution at baseline with a cohort of Danish blood donor.

Additional file 8: Table S6. Comparison of MBL distribution in the acute phase with a cohort of Danish blood donor. 


\section{Acknowledgements}

The County Council of Västerbotten, Umeå University, the Swedish Medical Society, Swedish Heart and Lung Foundation, Capio, and the Kempe Foundation supported this study. The authors wish to express their gratitude to the Västerbotten Intervention Project (VIP), the Northern Sweden MONICA project, the Mammary Screening Project, the Maternity Cohort of Northern Sweden, and the Medical Biobank and the funds that support these groups. We thank Åsa Ågren, Hubert Sjödin, Lennart Styrke and Eva Liedgren for expert technical assistance.

\section{Authors' contributions}

SS and PL designed the study, SJ extracted and evaluated patient data and performed statistical analyses. GJ contributed with statistical analysis including presentation of data in tables and figures. MÅ performed chemical analyses. SJ, SS and OW drafted the manuscript, and all authors revised the manuscript critically for important intellectual content. All authors approved the final version and are accountable for all aspects of the manuscript.

\section{Funding}

Funding that enabled collection, analysis, interpretation of data and writing the manuscript was received from the County Council of Västerbotten, Umeå University, the Swedish Medical Society, Capio, and the Kempe Foundation supported this study. SSÖ was supported by the Swedish Heart and Lung Foundation, and by the County Council of Västerbotten (ALF). Open access funding Umea University.

\section{Availability of data and materials}

All results and data are kept in the section of Anesthesiology and Intensive Care Medicine, Department of Surgical and Perioperative Science; Umeå University. These will be made available from the corresponding author on reasonable request.

\section{Ethics approval and consent to participate}

The study protocol was approved by the Regional Ethical Review Board in Umeå, diary number 06-144 M, 2010-40-23 and 2011/19-32 M and by the Swedish National Computer Data Inspector Board, and compiles with the Declaration of Helsinki. All participants gav informed consent for future use of data and blood samples at the moment of the baseline survey.

\section{Consent for publication}

Data was de-identified, after collection, and therefore there was no consent required from individual patients, according to the ethical approval.

\section{Competing interests}

The authors declare that they have no competing interests.

\section{Author details}

${ }^{1}$ Department of Surgical and Perioperative Sciences, Anesthesiology and Intensive Care Medicine, Umeå University, SE-901 87 Umeå, Sweden. ${ }^{2}$ Department of Public Health and Clinical Medicine, Medicine, Umeå University, SE-901 87 Umeå, Sweden.

\section{Received: 15 May 2019 Accepted: 31 July 2020}

Published online: 12 August 2020

\section{References}

1. Sandquist M, Wong HR. Biomarkers of sepsis and their potential value in diagnosis, prognosis and treatment. Expert Rev Clin Immunol. 2014; 10:1349-56.

2. Honore PM, Jacobs R, De Waele E, Spapen HD. Biomarkers to detect sepsis: a "burning" issue but still a long way to go*. Crit Care Med. 2014;42:2137-8.

3. Singh SS, Cheung RC, Wong JH, Ng TB. Mannose binding Lectin: a potential biomarker for many human diseases. Curr Med Chem. 2016;23:3847-60.

4. Radnay ZB, Udvardy M, Papp M, Harsfalvi J, Rejto L, Pal I, Illes A, Kiss A. Evaluation of mannose-binding Lectin is a useful approach to predict the risk of infectious complications following autologous hematopoietic stem cell transplantation. Transplant Proc. 2016;48:3397-405.

5. Jensenius JC, Jensen PH, McGuire K, Larsen JL, Thiel S. Recombinant mannanbinding lectin (MBL) for therapy. Biochem Soc Trans. 2003;31:763-7.

6. Sugiki T, Fujiwara T, Kojima C. Latest approaches for efficient protein production in drug discovery. Expert Opin Drug Discovery. 2014;9:1189-204.
7. Keizer MP, Wouters D, Schlapbach LJ, Kuijpers TW. Restoration of MBLdeficiency: redefining the safety, efficacy and viability of MBL-substitution therapy. Mol Immunol. 2014;61:174-84.

8. Malhotra R, Lu J, Holmskov U, Sim RB. Collectins, collectin receptors and the lectin pathway of complement activation. Clin Exp Immunol. 1994;97(Suppl 2):4-9.

9. Lipscombe RJ, Sumiya M, Hill AV, Lau YL, Levinsky RJ, Summerfield JA, Turner MW. High frequencies in African and non-African populations of independent mutations in the mannose binding protein gene. Hum Mol Genet. 1992;1:709-15.

10. Madsen HO, Garred P, Thiel S, Kurtzhals JA, Lamm LU, Ryder LP, Svejgaard A. Interplay between promoter and structural gene variants control basal serum level of mannan-binding protein. J Immunol. 1995;155:3013-20.

11. Madsen HO, Satz ML, Hogh B, Svejgaard A, Garred P. Different molecular events result in low protein levels of mannan-binding lectin in populations from Southeast Africa and South America. J Immunol. 1998;161:3169-75.

12. Garred P, Larsen F, Madsen HO, Koch C. Mannose-binding lectin deficiency-revisited. Mol Immunol. 2003;40:73-84.

13. Best $L G$, Ferrell RE, Decroo S, North KE, Maccluer JW, Zhang Y, Lee ET, Howard BV, Umans J, Palmieri V, Garred P. Genetic and other factors determining mannose-binding lectin levels in American Indians: the strong heart study. BMC Med Genet. 2009;10:5.

14. Ozkan H, Koksal N, Cetinkaya M, Kilic S, Celebi S, Oral B, Budak F. Serum mannose-binding lectin (MBL) gene polymorphism and low MBL levels are associated with neonatal sepsis and pneumonia. J Perinatol. 2012;32:210-7.

15. Holdaway J, Deacock S, Williams P, Karim Y. Mannose-binding lectin deficiency and predisposition to recurrent infection in adults. J Clin Pathol. 2016;69:731-6.

16. Roy S, Knox K, Segal S, Griffiths D, Moore CE, Welsh KI, Smarason A, Day NP, McPheat WL, Crook DW, et al. MBL genotype and risk of invasive pneumococcal disease: a case-control study. Lancet. 2002;359:1569-73.

17. Eisen DP, Dean MM, Boermeester MA, Fidler KJ, Gordon AC, Kronborg G, Kun JF, Lau YL, Payeras A, Valdimarsson H, et al. Low serum mannosebinding lectin level increases the risk of death due to pneumococcal infection. Clin Infect Dis. 2008:47:510-6.

18. Muller S, Schaffer T, Flogerzi B, Seibold-Schmid B, Schnider J, Takahashi K, Darfeuille-Michaud A, Vazeille E, Schoepfer AM, Seibold F. Mannan-binding lectin deficiency results in unusual antibody production and excessive experimental colitis in response to mannose-expressing mild gut pathogens. Gut. 2010;59:1493-500.

19. Monsey L, Best LG, Zhu J, DeCroo S, Anderson MZ. The association of mannose binding lectin genotype and immune response to chlamydia pneumoniae: the strong heart study. PLoS One. 2019;14: e0210640.

20. Ruseva M, Kolev M, Dagnaes-Hansen F, Hansen SB, Takahashi K, Ezekowitz A, Thiel S, Jensenius JC, Gadjeva M. Mannan-binding lectin deficiency modulates the humoral immune response dependent on the genetic environment. Immunology. 2009;127:279-88.

21. Takahashi K, Kurokawa K, Moyo P, Jung DJ, An JH, Chigweshe L, Paul E, Lee BL. Intradermal immunization with wall teichoic acid (WTA) elicits and augments an anti-WTA IgG response that protects mice from methicillinresistant Staphylococcus aureus infection independent of mannose-binding lectin status. PLoS One. 2013;8:e69739.

22. Zhao L, Ohtaki Y, Yamaguchi K, Matsushita M, Fujita T, Yokochi T, Takada H, Endo Y. LPS-induced platelet response and rapid shock in mice: contribution of O-antigen region of LPS and involvement of the lectin pathway of the complement system. Blood. 2002;100:3233-9.

23. Guttormsen HK, Stuart LM, Shi L, Carroll MC, Chen J, Kasper DL, Ezekowitz RA, Takahashi K. Deficiency of mannose-binding lectin greatly increases antibody response in a mouse model of vaccination. Clin Immunol. 2009; 130:264-71.

24. Garred P, Thiel S, Madsen HO, Ryder LP, Jensenius JC, Svejgaard A. Gene frequency and partial protein characterization of an allelic variant of mannan binding protein associated with low serum concentrations. Clin Exp Immunol. 1992;90:517-21.

25. Steffensen $R$, Thiel S, Varming K, Jersild C, Jensenius JC. Detection of structural gene mutations and promoter polymorphisms in the mannanbinding lectin (MBL) gene by polymerase chain reaction with sequencespecific primers. J Immunol Methods. 2000;241:33-42.

26. Eisen DP, Dean MM, Thomas P, Marshall P, Gerns N, Heatley S, Quinn J, Minchinton RM, Lipman J. Low mannose-binding lectin function is 
associated with sepsis in adult patients. FEMS Immunol Med Microbiol. 2006;48:274-82.

27. Huh JW, Song K, Yum JS, Hong SB, Lim CM, Koh Y. Association of mannosebinding lectin-2 genotype and serum levels with prognosis of sepsis. Crit Care. 2009;13:R176.

28. Gordon AC, Waheed U, Hansen TK, Hitman GA, Garrard CS, Turner MW, Klein NJ, Brett SJ, Hinds CJ. Mannose-binding lectin polymorphisms in severe sepsis: relationship to levels, incidence, and outcome. Shock. 2006;25:88-93.

29. Minchinton RM, Dean MM, Clark TR, Heatley S, Mullighan CG. Analysis of the relationship between mannose-binding lectin (MBL) genotype, $\mathrm{MBL}$ levels and function in an Australian blood donor population. Scand J Immunol. 2002;56:630-41.

30. Garred P, Strøm JJ, Quist L, Taaning E, Madsen HO. Association of mannose-binding lectin polymorphisms with sepsis and fatal outcome, in patients with systemic inflammatory response syndrome. J Infect Dis. 2003;188:1394-403.

31. Huh JW, Song K, Kim HJ, Yum JS, Hong SB, Lim CM, Koh Y. Serial changes in mannose-binding Lectin in patients with Sepsis. Tuberc Respir Dis (Seoul). 2018:81:305-10.

32. Dahl M, Tybjaerg-Hansen A, Schnohr P, Nordestgaard BG. A populationbased study of morbidity and mortality in mannose-binding lectin deficiency. J Exp Med. 2004;199:1391-9.

33. Heitzeneder S, Seidel M, Forster-Waldl E, Heitger A. Mannan-binding lectin deficiency - good news, bad news, doesn't matter? Clin Immunol. 2012;143:22-38

34. Mills TC, Chapman S, Hutton P, Gordon AC, Bion J, Chiche JD, Holloway PA, Stuber F, Garrard CS, Hinds CJ, et al. Variants in the mannose-binding Lectin gene MBL2 do not associate with Sepsis susceptibility or survival in a large European cohort. Clin Infect Dis. 2015;61:695-703.

35. Jacobsson S, Larsson P, Johansson G, Norberg M, Wadell G, Hallmans G, Winso O, Soderberg S. Leptin independently predicts development of sepsis and its outcome. J Inflamm (Lond). 2017;14:19.

36. Singer M, Deutschman CS, Seymour CW, Shankar-Hari M, Annane D, Bauer M, Bellomo R, Bernard GR, Chiche JD, Coopersmith CM, et al. The third international consensus definitions for Sepsis and septic shock (Sepsis-3). JAMA. 2016:315:801-10.

37. Knaus WA, Draper EA, Wagner DP, Zimmerman JE. APACHE II: a severity of disease classification system. Crit Care Med. 1985:13:818-29.

38. Vincent JL, Moreno R, Takala J, Willatts S, De Mendonca A, Bruining H, Reinhart CK, Suter PM, Thijs LG. The SOFA (Sepsis-related Organ Failure Assessment) score to describe organ dysfunction/failure. On behalf of the working group on Sepsis-related problems of the European Society of Intensive Care Medicine. Intensive Care Med. 1996;22:707-10.

39. Troldborg A, Hansen A, Hansen SW, Jensenius JC, Stengaard-Pedersen K, Thiel S. Lectin complement pathway proteins in healthy individuals. Clin Exp Immunol. 2017;188:138-47.

40. Kildey K, Rooks K, Weier S, Flower RL, Dean MM. Effect of age, gender and mannose-binding lectin (MBL) status on the inflammatory profile in peripheral blood plasma of Australian blood donors. Hum Immunol. 2014; 75:973-9.

41. Taylor ME, Brickell PM, Craig RK, Summerfield JA. Structure and evolutionary origin of the gene encoding a human serum mannose-binding protein. Biochem J. 1989:262:763-71.

42. Arai T, Tabona P, Summerfield JA. Human mannose-binding protein gene is regulated by interleukins, dexamethasone and heat shock. Q J Med. 1993; 86:575-82.

43. Thiel S, Holmskov U, Hviid L, Laursen SB, Jensenius JC. The concentration of the C-type lectin, mannan-binding protein, in human plasma increases during an acute phase response. Clin Exp Immunol. 1992;90:31-5.

44. Dean MM, Minchinton RM, Heatley S, Eisen DP. Mannose binding lectin acute phase activity in patients with severe infection. J Clin Immunol. 2005; 25:346-52.

45. Herpers BL, Endeman $\mathrm{H}$, de Jong BA, de Jongh BM, Grutters JC, Biesma DH, van Velzen-Blad $\mathrm{H}$. Acute-phase responsiveness of mannose-binding lectin in community-acquired pneumonia is highly dependent upon MBL2 genotypes. Clin Exp Immunol. 2009;156:488-94.

46. Ytting $\mathrm{H}$, Christensen IJ, Basse L, Lykke J, Thiel S, Jensenius JC, Nielsen HJ. Influence of major surgery on the mannan-binding lectin pathway of innate immunity. Clin Exp Immunol. 2006;144:239-46.

47. Fidler KJ, Wilson P, Davies JC, Turner MW, Peters MJ, Klein NJ. Increased incidence and severity of the systemic inflammatory response syndrome in patients deficient in mannose-binding lectin. Intensive Care Med. 2004;30: 1438-45.

48. Sprong T, Mollnes TE, Neeleman C, Swinkels D, Netea MG, van der Meer JW, van Deuren M. Mannose-binding lectin is a critical factor in systemic complement activation during meningococcal septic shock. Clin Infect Dis. 2009:49:1380-6.

49. Genster N, Takahashi M, Sekine H, Endo Y, Garred P, Fujita T. Lessons learned from mice deficient in lectin complement pathway molecules. Mol Immunol. 2014:61:59-68.

50. Berger SP, Daha MR. Emerging role of the mannose-binding lectindependent pathway of complement activation in clinical organ transplantation. Curr Opin Organ Transplant. 2011;16:28-33.

51. Cedzynski M, Szemraj J, Swierzko AS, Bak-Romaniszyn L, Banasik M, Zeman K, Kilpatrick DC. Mannan-binding lectin insufficiency in children with recurrent infections of the respiratory system. Clin Exp Immunol. 2004;136: 304-11.

52. Chen J, Xu Z, Ou X, Wang M, Yang X, Li Q. Mannose-binding lectin polymorphisms and recurrent respiratory tract infection in Chinese children. Eur J Pediatr. 2009;168:1305-13.

53. Super M, Thiel S, Lu J, Levinsky RJ, Turner MW. Association of low levels of mannan-binding protein with a common defect of opsonisation. Lancet. 1989:2:1236-9.

\section{Publisher's Note}

Springer Nature remains neutral with regard to jurisdictional claims in published maps and institutional affiliations.
Ready to submit your research? Choose BMC and benefit from:

- fast, convenient online submission

- thorough peer review by experienced researchers in your field

- rapid publication on acceptance

- support for research data, including large and complex data types

- gold Open Access which fosters wider collaboration and increased citations

- maximum visibility for your research: over $100 \mathrm{M}$ website views per year

At $\mathrm{BMC}$, research is always in progress.

Learn more biomedcentral.com/submissions 